\title{
A IMPORTÂNCIA DO TRABALHO COLABORATIVO NO PROCESSO DE INCLUSÃO ESCOLAR DE ESTUDANTES SURDOS
}

Denner Dias Barros, Danielle Aparecida do Nascimento dos Santos, Ana Virginia Isiano Lima, Ana Mayra Samuel da Silva, Klaus Schlünzen Júnior.

Universidade Estadual Paulista - UNESP, Licenciatura em Matemática, Presidente Prudente, SP. E-mail: dennerdias12@gmail.com

Agência de fomento: FAPESP

\section{RESUMO}

O presente artigo apresenta resultados da pesquisa de iniciação científica intitulada "O ensino de conceitos matemáticos para estudantes surdos em uma perspectiva inclusiva" realizada no ano de 2015. O objetivo deste estudo foi verificar de que maneira os professores que atuam no Atendimento Educacional Especializado e o professor de Matemática da Sala Regular podem trabalhar colaborativamente para construir um Plano de Ensino Individualizado para o trabalho com resolução de problemas nas aulas de Matemática e favorecer a participação de estudantes surdos. A metodologia foi realizada a partir de um estudo de caso desenvolvido em uma escola estadual da cidade de Presidente Prudente - SP. Dentre os resultados da pesquisa podemos ressaltar a importância da formação inicial do professor que trabalha na sala regular proporcionar discussões sobre educação inclusiva. Além disso, verificamos a importância do trabalho colaborativo para proporcionar condições de plena participação dos estudantes surdos.

Palavras-chave: Trabalho colaborativo, estudantes surdos, aulas de Matemática, resolução de problemas, Educação Especial na perspectiva da Educação Inclusiva.

\section{THE IMPORTANCE OF COLLABORATIVE WORK IN THE PROCESS OF EDUCATION INCLUSION OF DEAF STUDENTS}

\begin{abstract}
This article presents results of scientific initiation research entitled "The teaching of mathematical concepts for deaf students in an inclusive perspective" held in the year 2015. The objective of this study was to determine how the teacher who work in the Educational Service Specialist and the teacher of Mathematics can work together to build an Individualized Education Plan to work with problem solving in mathematics classrooms and to encourage the participation of deaf students. The methodology consisted of a case study in a state school in the city of Presidente Prudente - SP. Among the survey results we can emphasize the importance of the initial training of teachers working in regular room provide discussions on inclusive education. Furthermore, we note the importance of collaborative work to provide conditions for full participation of deaf students.

Keywords: Collaborative work, deaf students, Mathematics classes, problems solving, Especial Education in perspective of Inclusive Education.
\end{abstract}




\section{INTRODUÇÃO}

A inclusão das pessoas surdas em uma comunidade majoritariamente ouvinte, encontrou e ainda encontra fatores que dificultam ou que apenas conseguiram ser superados ou amenizados mediante muita luta e com a realização de mobilizações com a busca da desmistificação de algumas características pejorativas atribuídas a estas pessoas.

No Brasil, os sistemas de ensino têm o dever de matricular todos os estudantes, cabendo às escolas organizarem-se para o atendimento aos Estudantes Público-Alvo da Educação Especial (EPAEE) e garantir as condições necessárias para oferecer a estes estudantes um aprendizado de qualidade. Isso está regulamentado pelas Diretrizes Nacionais para a Educação Especial na Educação Básica (Resolução do Conselho Nacional de Educação/Câmara de Educação Básica no 2/2001).

Quanto à escolarização dos surdos, existem três concepções básicas que ao longo do tempo foram sendo adotadas ou refutadas, são elas: a Oralista, a Comunicação Total e o Bilinguismo. Essas propostas também ora supunham que o aluno surdo deveria estar na classe comum, ora na classe especial ou até em escolas especiais.

Uma abordagem pautada no Oralismo pressupunha a capacitação de pessoas com surdez a partir da utilização da língua falada da comunidade na qual o surdo estava inserido. Portanto, deveria fazer uso da leitura labial e da oralidade desenvolvida por exercícios exaustivos de treinamento para "aprender a falar".

Porém, essa proposta não obteve êxito, já que buscava a normatização das diferenças, repudiando totalmente o uso de língua de sinais, que são naturalmente desenvolvidas pelas pessoas surdas, e entendendo a educação do surdo numa perspectiva de reabilitação, como retrata Skliar (1997, p.46)

A concepção do sujeito surdo ali presente diz respeito exclusivamente a uma dimensão clínica - a surdez como deficiência, os surdos como sujeitos patológicos - numa perspectiva terapêutica - a surdez deve reeducar-se e/ou curar-se, os surdos devem ser reeducados e/ou curados.

A Comunicação Total, diferentemente da abordagem Oralista, já compreende a pessoa surda com todas suas características e especificidades. Nessa concepção de ensino é aceita qualquer forma de comunicação, priorizando a interação social. Entretanto, não se valorizava a língua de sinais. Os textos orais e escritos, a linguagem gestual e visual não possibilitava uma plena participação dos estudantes surdos no âmbito escolar, o que acabava por segregar estes estudantes. A surdez ainda era vista como algo que deveria ser "curado".

O Bilinguismo, por sua vez, visa a alfabetização da pessoa surda primeiramente na língua de sinais e depois na língua da comunidade ouvinte na modalidade escrita. É adotado como método atual de ensino das pessoas surdas no Brasil, onde a primeira língua é a Língua Brasileira de Sinais (Libras) e a segunda é o Português escrito.

A abordagem bilíngue respeita a língua natural do surdo e oportuniza a construção de um ambiente que favorece a aprendizagem escolar. Para Quadros (1997), a língua de sinais surge pelas mesmas necessidades naturais e específicas do ser humano de fazer uso de uma linguagem específica para expressar ideias, ações e sentimentos. Assim, a língua de sinais não é apenas um meio de comunicação entre pessoas surdas, mas também entre surdos e ouvintes.

Entretanto, a língua de sinais não pode ser entendida como um fim. O aluno surdo ser fluente em Libras não basta, mas a aquisição da língua de sinais é um requisito essencial, na construção da identidade da pessoa surda e no seu processo de inclusão.

Outros dificultadores podem ser encontrados quando visamos a plena inclusão do estudante surdo no âmbito escolar. Nessa perspectiva, Nogueira e Machado (1995) e Gil (2007), afirmam, por exemplo, que os professores dos estudantes surdos consideram a Matemática como 
uma disciplina que não apresenta grandes dificuldades para esses estudantes, mas com exceção do ensino de resolução de problemas, que por serem naturalmente formulados em Língua Portuguesa, ocasionam uma dificuldade na interpretação dos enunciados.

Fávero (2010) complementa que esse é um problema não só dos estudantes surdos, mas é comum para surdos e ouvintes, pois implica a necessidade de habilidades em leitura funcional e lógica do sistema de medidas e numérico.

Portanto, quando o professor busca metodologias diferenciadas da abordagem por intermédio da resolução de problemas nas aulas de Matemática, não estamos favorecendo apenas os alunos surdos. Todos os alunos ganham neste processo de repensar o ensino e valorizar as diferenças dentro da sala de aula.

Considerando essas perspectivas, o objetivo da pesquisa foi verificar de que maneira os professores que atuam no Atendimento Educacional Especializado e o professor de Matemática da Sala Regular podem trabalhar colaborativamente para construir um Plano de Ensino Individualizado para o trabalho com resolução de problemas nas aulas de Matemática e favorecer a participação de estudantes surdos.

\section{METODOLOGIA}

A pesquisa intitulada "O Ensino De Conceitos Matemáticos Para Estudantes Surdos Em Uma Perspectiva Inclusiva" foi subsidiada pela Fundação de Amparo à Pesquisa do Estado de São Paulo (FAPESP), processo no 2014/19686-2 no ano de 2015.

De cunho qualitativo, a pesquisa buscou, apoiada nas ideias de Richardson $(1999$, p.80)

Os estudos que empregam uma metodologia qualitativa podem descrever a complexidade de determinado problema, analisar a interação de certas variáveis, compreender e classificar processos dinâmicos vividos por grupos sociais, contribuir no processo de mudança de determinado grupo e possibilitar, em maior nível de profundidade, o entendimento das particularidades do comportamento dos indivíduos.

A pesquisa tem autorização do Comitê de Ética em Pesquisa, número CAAE: 48407015.9.0000.5402.

Foi composta de três etapas que foram desenvolvidas em uma escola da rede estadual de ensino do município de Presidente Prudente - SP: ambientação, desenvolvimento dos PEI e aplicação. Dado que a pesquisa é de profundidade de iniciação científica, optou-se pela realização de um estudo de caso, sendo o foco do estudo direcionado a uma turma do 3 o ano do Ensino Médio da escola campo.

Em um primeiro momento, foi realizada uma pesquisa nos bancos de dados por artigos, dissertações e teses sobre a temática para dar o aporte teórico.

Após este estudo, foi realizado o primeiro contato com a escola campo da pesquisa, onde foram observadas algumas aulas de Matemática e atividades realizadas no Atendimento Educacional Especializado (AEE) com uma estudante, denominada A, surda, matriculada no 3ㅇ ano do Ensino Médio.

Durante a ambientação foram realizadas entrevistas com a professora de Matemática e a professora da Sala de Recursos, além de atividades diagnósticas com a estudante $A$.

A segunda etapa foi composta da seleção de um tema e da elaboração em conjunto com as duas professoras de um Plano de Ensino Individualizado (PEI) baseado na proposta curricular do estado de São Paulo.

A última etapa contou com a aplicação do PEI, elaborado colaborativamente, numa perspectiva inclusiva, durante as aulas de Matemática na sala regular, com os estudantes, visando a participação de todos. 


\section{RESULTADOS}

Para a elaboração do Plano de Ensino Individualizado, visando a plena participação da estudante $A$, nas aulas de Matemática, foi levado em consideração o Currículo do Estado de São Paulo, o Plano Anual de Ensino adotado pela Sala de Recursos da escola e o Plano Bimestral de Ensino da Aluna A na Sala de Recursos.

De acordo com o Currículo do Estado de São Paulo e os cadernos do Programa -São Paulo faz escola foi selecionada uma situação de aprendizagem que condizia com o período de aplicação do PEl e com os objetivos de trabalho estabelecidos para a estudante $A$.

A situação de aprendizagem selecionada foi: "Situação De Aprendizagem 5: A Apresentação De Dados Estatísticos: Gráficos E Tabelas." Esta situação de aprendizagem engloba os seguintes conteúdos e temas: gráficos de frequências e histogramas; gráficos compostos por mais de um dos tipos clássicos conhecidos; pictogramas.

No desenvolvimento do $\mathrm{PEI}$, pretendíamos que a estudante $\mathrm{A}$ pudesse desenvolver algumas competências e habilidades estabelecidas no Plano Anual de Ensino, como: Trabalhar temas atuais e estimular o exercício da cidadania; propiciar atividades extraclasses; Aulas diferenciadas com trabalho em grupo, seminários, pesquisas.

Em momentos de encontro entre a professora de Matemática, a professora da Sala de Recursos e o pesquisador discutiram sobre como tornar o trabalho idealizado para ser desenvolvido dentro do currículo de Matemática do 3ำ ano do Ensino Médio poderia contemplar todos os alunos de maneira efetiva.

A professora da Sala de Recursos apresentou-se disposta para auxiliar no que fosse necessário no desenvolvimento das atividades dando suporte durante o APE.

Foi então que se iniciou a elaboração e estruturação do PEI em uma perspectiva inclusiva e colaborativa. Inicialmente foram elencados alguns apontamentos importantes sobre a aluna A. Suas habilidades e potencialidades, bem como, sobre seu desempenho e participação nas aulas de Matemática e durante o APE.

Depois, foram ressaltadas quais habilidades e conteúdos, as professoras concordavam ser mais importantes de serem trabalhadas na atividade com a estudante A. Bem como, se estipularam os objetivos das atividades e descreveram as atividades que seriam realizadas e como seria realizada a avaliação da mesma.

Foi decidido que para contemplar os objetivos da situação de aprendizagem proposta, os estudantes deveriam realizar uma pesquisa de um tema de interesse e apresentar os dados coletados através de gráficos e tabelas.

Então, depois da realização de um debate em sala de aula, a turma optou por realizar o seguinte problema: "Investigar a profissão com a qual mais se identificam, buscando levantar dados relevantes e apresenta-los de maneira organizada e sistematizada, fazendo uso das ferramentas da estatística apresentadas durante as aulas de Matemática. Através desta investigação devem repensar sobre suas perspectivas futuras de trabalho e estudo."

No decorrer das atividades a colaboração entre a professora da Sala de Recursos, a professora de Matemática da sala regular e a professora interlocutora de Libras se mostrou essencial para que a estudante A pudesse participar plenamente de todas as atividades propostas.

\section{DISCUSSÃO}

Ao pensar no planejamento de ensino, temos que refletir inicialmente sobre o currículo no qual este planejamento estará pautado. E, os currículos devem estar sempre ajustados para atender à heterogeneidade de estudantes presentes no contexto escolar.

Pacheco et al. (2007, p. 97) aponta quais aspectos do currículo são importantes para garantir a equidade de oportunidades dentro da sala de aula: 
É importante que as escolas criem uma política global de inclusão e descrevam essa política em seu currículo escolar. Essa é uma indicação da capacidade e da vontade das escolas de melhorar as habilidades sociais dos alunos assim como suas habilidades acadêmicas.

O que parece ser benéfico para alguns alunos provavelmente o será para a turma. As escolas devem ter isso em mente a fim de compreender que as necessidades especiais de alguns alunos podem dar à escola uma oportunidade de melhorar o trabalho escolar para todos.

O professor da turma é responsável pela educação de cada aluno em sua turma. Para atender às variadas necessidades dos alunos, o currículo e o trabalho de aula devem ser aplicados a todos os alunos e, ao mesmo tempo, ser flexíveis e ajustáveis.

A inclusão escolar deve ser vista como um processo que favorece a todos e não apenas aos estudantes com deficiência. Para Sartoretto (2011), o direito à educação é oriundo do direito primordial à convivência, até porque é na convivência com seres humanos - normais ou diferentes - que o ser humano mais aprende. A maior parte do que o ser humano aprende, o aprende na convivência, na interação com o outro, na adaptação, enfrentando os problemas do dia-a-dia.

O PEI deve abranger diversos aspectos educacionais, desde o trabalho fora da sala de aula, como na SR e na sala comum. Para Pacheco et. al. (2007, p. 97)

Um plano educacional individualizado é uma estrutura para a colaboração dos professores, dos pais e do serviço de apoio em criar um currículo para um indivíduo. Eles compartilham a responsabilidade pela criação do plano educacional especializado do aluno. O papel do serviço de apoio mudou, deixando de ter a principal responsabilidade pela criação de um plano educacional especializado para agir principalmente como consultores.

Para Capellini e Mendes (2007) numa perspectiva de uma -escola para todos é necessário que os professores sejam capazes de ensinar com objetivos comuns, independente de seus alunos terem alguma deficiência, cabendo a eles fazerem a adequação curricular necessária.

Ao planejar o PEI é importante que todos os agentes que participam de sua elaboração coloquem a mesma ênfase em aspectos diferenciados que influenciam na educação do estudante. Para Pacheco et. al. (2007), é necessário valorizar devidamente os aspectos emocionais, sociais e acadêmicos. Para garantir então, tanta participação do estudante nas aulas quanto possível, promovendo a solidariedade dentro da sala de aula, não deixando nenhum estudante de fora.

\section{CONCLUSÃO}

Alcançar o patamar de uma escola inclusiva não é uma tarefa fácil. Porém, ao pensar nas especificidades de um estudante na sala de aula, o professor é levado a refletir sobre como à adequação de sua aula para garantir a participação deste estudante em específico pode favorecer a participação de todos os estudantes em suas aulas.

Além disso, quando todos os profissionais do ambiente escolar estão comprometidos e trabalham colaborativamente isso proporciona vários benefícios, como a melhor interação entre todas as pessoas e o desenvolvimento de ações mais inclusivas. 


\section{REFERÊNCIAS}

BRASIL. Ministério da Educação. Secretaria de Educação Especial. Diretrizes Nacionais para a Educação Especial na Educação Básica. Brasília: MEC/SEESP, 2001.

CAPELLINI, V. L. M. F.; MENDES, E. G. O ensino colaborativo favorecendo o desenvolvimento profissional para inclusão escolar. Educere et Educare, Revista de Educação, v.2, n.4, p.113-128, 2007.

FÁVERO, M. H. Resolução de problemas, surdez e a língua de sinais: Uma questão para a psicologia do conhecimento e para a educação matemática. In: Encontro Nacional de Educação Matemática, 10, 2010, Salvador, Anais... Salvador, 2010.

GIL, R. S. A. Educação Matemática dos Surdos: um estudo das necessidades formativas dos professores que ensinam conceitos matemáticos no contexto de educação de deficientes auditivos em Belém/PA. Dissertação (Mestrado em Ensino de Ciências e Matemática). Universidade do Pará. Belém, 2007.

NOGUEIRA, C.M.I e MACHADO, E. L.O ensino de matemática para deficientes auditivos: uma visão psicopedagógica. 1995. Relatório final da pesquisa - Departamento de Matemática Universidade Estadual de Maringá, Maringá/ PR.

PACHECO. J. (Org.). Caminhos para a inclusão: um guia para o aprimoramento da equipe escolar. Porto Alegre: Artmed, 2007.

QUADROS, R.M. Educação de surdos: a aquisição da linguagem. Porto Alegre: Artes Médicas, 1997.

RICHARDSON, R. J. et al. Pesquisa social: métodos e técnicas. 2. ed. São Paulo: Atlas, 334 p., 1999.

SARTORETTO, M. L. Os Fundamentos da Educação Inclusiva. 2011. Disponível em http://assistiva.com.br/Educa\%C3\%A7\%C3\%A3o_Inclusiva.pdf. Acesso em 13 de jul. 2016.

SKLIAR, C. Uma análise preliminar das variáveis que intervêm no Projeto de Educação Bilíngüe para os Surdos. Espaço Informativo Técnico Científico do INES, Rio de Janeiro, v.6, p. 49-57, 1997. 